\title{
AVALIAÇÃO DO NÍVEL DA VULNERABILIDADE DO SOLO DEVIDO À PRESENÇA DE TERMELÉTRICA A CARVÃO (FIGUEIRA, PR- BRASIL)
}

Marlene Flues* e Patrícia Hama

Centro de Química e Meio Ambiente, Instituto de Pesquisas Energéticas e Nucleares, CP 11049, 05422-970 São Paulo - SP Adalgiza Fornaro

Departamento de Ciências Atmosféricas, Instituto de Astronomia, Geofísica e Ciências Atmosféricas, Universidade de São Paulo, Rua do Matão, 1226, 05508-900 São Paulo - SP

Recebido em 14/6/02; aceito em 19/12/02

\begin{abstract}
EVALUATION OF THE SOIL SENSITIVITY FOR THE ACIDITY NEAR A COAL FIRED POWER PLANT (FIGUEIRA, PRBRAZIL). Rainwater samples were analyzed during a one-year period (June 1999 - June 2000) and presented concentration of $\mathrm{pH}=4.9$ (volume weight mean). The ions concentrations results showed a high sulfate concentration $\left(35 \mu \mathrm{mol} \mathrm{L} \mathrm{L}^{-1}\right)$, followed by the cations concentration of sodium, calcium and ammonium (35, 16 and $30 \mu \mathrm{mol} \mathrm{L}^{-1}$, respectively). Due to the great contribution of these cations in the sulfate neutralization action, the rainwater of this region had only a light acid characteristic. The soil characteristic was acid and the bioavailable concentration of the alkaline cations $(\mathrm{Ca}, \mathrm{Mg}$ and $\mathrm{K}$ ) presented high calcium concentrations $\left(1001 \pm 357 \mathrm{mg} \mathrm{kg}^{-1}\right)$ compared with the other cations. The determination of soil sensitivity to acid rain was calculated by the ratio $\mathrm{BC} / \mathrm{Al}^{3+}\left(\mathrm{BC}=\mathrm{Ca}^{2+}+\mathrm{Mg}^{2+}+\mathrm{K}^{+}\right)$and presented the average value of $5.1 \pm 3.3$. This preliminary evaluation of soil susceptibility by the ratio $\mathrm{BC} / \mathrm{Al}^{3+}$ showed that the local soil and vegetation type (tropical Savannah) were sensitive to acid deposition. The long term of this impacting condition (acid rain, high sulfate deposition) could be harmful to the soil and vegetation quality.
\end{abstract}

Keywords: soil; critical load; acid rain.

\section{INTRODUÇÃO}

Com a necessidade de ampliar a oferta de energia do país, as termelétricas a carvão apresentam-se como uma das alternativas interessantes. Para que essa tecnologia seja posta em prática, é importante que as novas termelétricas sejam implantadas, seguindo o modelo de desenvolvimento sustentável. Para tanto, é fundamental uma avaliação de custo/benefício, do ponto de vista econômico e ambiental ${ }^{1}$.

O carvão brasileiro apresenta alto teor de cinzas e $7 \%$ de pirita. A viabilidade da sua aplicação em termelétricas somente é possível se a usina for construída nas proximidades das minas de carvão, reduzindo o custo de transporte. Por essa razão o sul do Brasil, onde se encontram as principais jazidas de carvão, é privilegiado com esta opção de geração de energia ${ }^{2}$.

A combustão do carvão opera em fornos a $1700{ }^{\circ} \mathrm{C}$ para a produção de energia elétrica. No processo de combustão a maior parte do material mineral do carvão é fundida. A porção de cinza pesada, junto com o material orgânico não queimado, deposita-se no fundo do forno. Por outro lado, a cinza leve é carreada através do queimador junto com o fluxo de gases e compostos minerais voláteis para a chaminé e, dependendo do sistema de controle de emissão, a maior parte da cinza é coletada. A quantidade de cinza liberada (cinza volante) para a atmosfera varia entre 0,5 e $10 \%$, dependendo da idade e sofisticação da usina ${ }^{3}$.

Juntamente com as cinzas volantes também são liberadas grandes quantidades de gases como $\mathrm{SO}_{2}$ e $\mathrm{NO}_{\mathrm{x}}\left(\mathrm{NO}\right.$ e $\mathrm{NO}_{2}$ ) que, lançados na atmosfera, contribuem para a precipitação ácida na região. A chu-

*e-mail: mflues@net.ipen.br va ácida caracteriza-se por apresentar valores de $\mathrm{pH}$ inferiores a 5,6 representando o valor da acidez da água pura em equilíbrio com concentrações atmosféricas de $\mathrm{CO}_{2}^{4}$.

A chuva é um processo eficiente de remoção de material particulado e gases poluentes presentes na atmosfera. A quantidade de substâncias depositadas e/ou transportadas pela chuva é influenciada por emissão local, altitude em relação ao nível do mar e condições meteorológicas como campo de vento, tamanho da gota de chuva e altura da camada de mistura ${ }^{5}$.

Poucos trabalhos são encontrados na literatura sobre avaliação da composição química de águas de chuva em regiões sob influência de termelétricas a carvão. Na Espanha foi estudada a deposição úmida em região sob influência de termelétrica com produção de 1050 MWe de energia ${ }^{6}$. Outro estudo avaliando a influência de termelétrica a carvão na composição química de águas de chuva foi realizado na região de Figueira, estado do Paraná, Brasil, que produz 10 MWe de energia, sendo parte dos resultados apresentados no presente artigo ${ }^{7}$.

Os constituintes químicos presentes no ar influenciam o ciclo de água atmosférico, como consequiência o material depositado pela chuva pode causar graves efeitos sobre os ecossistemas terrestres e aquáticos, causando a acidificação do solo, águas superficiais e vegetação. Esses efeitos variam geograficamente, dependendo do compartimento do ecossistema em questão e da quantidade da deposição ácida, ou seja, da sensibilidade do receptor, expressa pelo conceito de carga crítica ("critical load" - CL), sendo este amplamente utilizado no desenvolvimento de estratégias com o objetivo de reduzir a emissão de poluentes. As cargas críticas são determinadas para algumas espécies poluentes de vários ecossistemas e tipos específicos de receptores: solos, vegetação de florestas e águas superficiais ${ }^{8,9}$.

A Comissão Econômica das Nações Unidas para Europa (UNECE - United Nations Economic Commission for Europe) utiliza o concei- 
to de carga crítica como base para decisões referentes ao desenvolvimento de legislações para o controle das emissões de poluentes do $\operatorname{ar}^{8-10}$. Segundo Nilsson e Grennfelt ${ }^{11}$, a carga crítica indica a sensibilidade de determinado meio, definindo o nível de exposição à poluição que esse meio pode tolerar sem produzir danos de longa duração.

Especificamente, a carga crítica para acidez de solos é definida como "a estimativa da maior deposição de compostos ácidos, os quais não causem mudanças químicas no solo, e que poderiam, com o tempo, levar a efeito prejudicial significativo da estrutura e função do ecossistema" 11 .

A dinâmica da acidificação do solo depende das seguintes características: grau de intemperismo, capacidade de adsorção de sulfato e capacidade de troca catiônica. Esta acidificação conduz ao aumento da concentração de alumínio na solução solo e, conseqüentemente, aumenta o risco de dano à vegetação, além de provocar mudanças na disponibilidade de nutrientes (magnésio e fosfato) e suas formas (nitrato e amônio). Estas mudanças influem na fertilidade do solo podendo ser impactantes sobre a estrutura e função da vegetação ${ }^{11}$.

O valor da carga crítica absoluta para o solo de determinada região depende de vários fatores e não somente do material de origem do solo. Dentre os fatores de influência estão a precipitação anual, o tipo de vegetação, textura do solo, drenagem, topografia (inclinação), profundidade do solo, capacidade de adsorção de sulfato e deposição de cátions básicos da atmosfera, além de fatores meteorológicos e hidrológicos. Estes fatores podem apresentar influência igual, mais baixa ou muito pequena na ação de acidificar o solo ${ }^{11}$.

Para investigar os efeitos adversos da atividade da termelétrica a carvão na região de Figueira, avaliou-se a composição química dos eventos de chuva durante o período de Junho de 1999 a Junho de 2000, cujos detalhes experimentais e resultados referentes exclusivamente às águas de chuva já foram publicados ${ }^{7}$, assim como a vulnerabilidade do solo e da vegetação à deposição ácida pelo conceito de carga crítica parcial, ou seja, a relação $\left(\mathrm{Ca}^{2+}+\mathrm{Mg}^{2+}+\mathrm{K}^{+}\right) / \mathrm{Al}^{3+}$.

\section{DESCRIÇÃO DO LOCAL}

A usina termelétrica a carvão localiza-se no município de Figueira, Nordeste do Estado do Paraná (2352' Sul e 50²4' Oeste), a 315 km da capital Curitiba (Figura 1). O contexto climático de Figueira é $\mathrm{Cfb}$, ou seja, subtropical úmido mesotérmico com médias máximas de $26{ }^{\circ} \mathrm{C}$ e mínimas de $11^{\circ} \mathrm{C}$. A umidade relativa média do ar é de $67 \%$ e o índice pluviométrico anual médio dos últimos 10 anos é de $1398 \mathrm{~mm}$. Na vegetação local predomina o cerrado (tropical Savannah) e o relevo é suave e ondulado, com altitude média de $600 \mathrm{~m}$. O solo é classificado como podzólico vermelho-amareloálico-abrúptico, considerado ácido, com baixa saturação de bases, alta saturação de alumínio trocável e argila de alta atividade. Na região de Figueira, a termelétrica (10 MWe) e a mina de carvão são as principais atividades industriais.

\section{METODOLOGIA}

\section{Águas de chuva}

Utilizou-se coletor de politereftalato de etileno (PET) com 17 $\mathrm{cm}$ de diâmetro, apoiado em suporte a $1 \mathrm{~m}$ do solo, para coleta de 73 amostras de águas de chuvas, correspondentes a 30 eventos de precipitação, com contribuição da deposição seca e úmida ("bulk deposition"). Após cada evento de chuva o volume total foi anotado, seguido de retirada de alíquota de $150 \mathrm{~mL}$, filtrada em papel de filtro comum e estocada no congelador ${ }^{7}$.

Determinaram-se as concentrações de cátions $\left(\mathrm{Na}^{+}, \mathrm{NH}_{4}^{+}, \mathrm{K}^{+}\right.$, $\mathrm{Mg}^{2+}$ e $\left.\mathrm{Ca}^{2+}\right)$ e ânions $\left(\mathrm{SO}_{4}^{2-}, \mathrm{NO}_{3}^{-} \mathrm{e} \mathrm{Cl}^{-}\right)$com cromatógrafo de íons

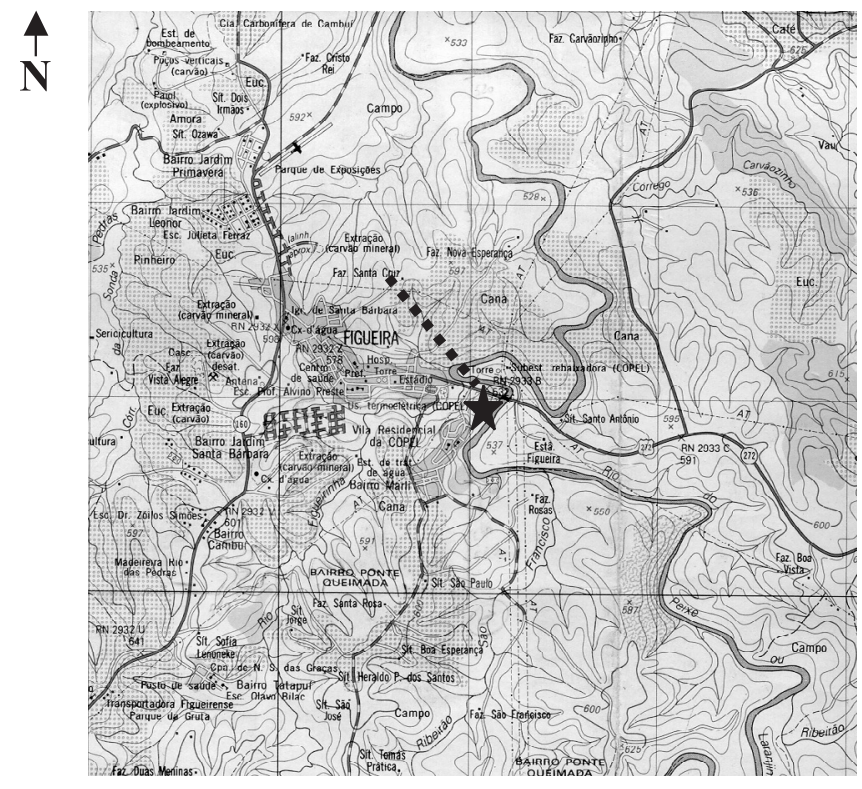

Figura 1. Mapa da região da Termelétrica de Figueira, Paraná (2352' Sul e 50²4'Oeste) Escala: 1: 50.000. Pontos de amostragem de solos na direção predominante dos ventos $(\mathrm{NW})$; * Termelétrica Figueira

Dionex-DX120, acoplado a integrador (Waters-100). Para a análise de cátions utilizou-se coluna catiônica (HPIC-CS14 Dionex), eluente $10 \mathrm{mmol} \mathrm{L}^{-1}$ de ácido metanosulfônico e fluxo $0,86 \mathrm{~mL} \mathrm{~min}^{-1}$. Para análise dos ânions utilizou-se coluna aniônica (HPIC-AS14-Dionex), como eluente a solução $1,0 \mathrm{mmol} \mathrm{L}^{-1} \mathrm{Na}_{2} \mathrm{CO}_{3} / 3,5 \mathrm{mmol} \mathrm{L}-1 \mathrm{NaHCO}_{3}$ e fluxo $1,2 \mathrm{~mL} \mathrm{~min}^{-1}$. Utilizou-se pHmetro de campo Digimed modelo 330 e condutivímetro de campo Orion, para medidas de $\mathrm{pH}$ e de condutividade, respectivamente, a $25^{\circ} \mathrm{C}^{7}$.

\section{Solo}

Coletaram-se 14 amostras de solo a partir da termelétrica, na direção predominante dos ventos (NW), sendo 11 amostras em intervalos de $100 \mathrm{~m}$ até $1200 \mathrm{~m}$ e as outras $3 \mathrm{em} 2200 \mathrm{~m}, 3000 \mathrm{~m}$ e $6000 \mathrm{~m}$. Em cada ponto coletou-se $1 \mathrm{~kg}$ de solo no horizonte A (0-25 $\mathrm{cm})$, sendo as amostras identificadas pela distância da usina. Secaram-se as amostras à temperatura ambiente, seguido de peneiramento (2x2 mm) e homogeneização. Para caracterização do solo determinou-se em cada amostra a granulometria (\% de argila, silte e areia) ${ }^{12}$, $\mathrm{pH}$, porcentagem de matéria orgânica $(\mathrm{MO})^{13}$ e a capacidade de troca cationnica $(\mathrm{CTC})^{14}$. Todas as análises foram feitas em triplicatas.

A concentração biodisponível dos cátions $\mathrm{Ca}^{2+}, \mathrm{Na}^{+}, \mathrm{K}^{+}, \mathrm{Mg}^{2+} \mathrm{e}$ $\mathrm{Al}^{3+}$ no solo foi obtida pela extração com solução de EDTA- $\mathrm{NH}_{4}^{+}$ $0,05 \mathrm{~mol} \mathrm{~L}^{-1}, \mathrm{pH}=7^{15}$. A determinação dos cátions na solução extraída foi realizada através da técnica de Espectrometria de Emissão Atômica com Plasma Indutivo (ICP-OES), Espectro Flame M 120 Spectro.

\section{Método para cálculo da carga crítica (CL)}

A confiabilidade da carga crítica calculada é fortemente influenciada pela qualidade dos limites críticos usados para os diferentes elementos. Para aspectos abióticos como a química de solos e a qualidade de águas subterrâneas os limites críticos são claros, pois as relações dose-efeito (p.e., efeito da deposição ácida e mudanças no conteúdo e/ou saturação de Al-hidróxidos) são bem conhecidas. 
Entretanto, para indicadores bióticos como danos a raízes, é mais difícil determinar limites críticos, os quais podem ser utilizados como níveis limítrofes, abaixo dos quais os efeitos são negligenciáveis. Danos às raízes envolvem reações bastante complexas, as quais podem ser causadas por uma combinação de fatores como secas e condições do solo adversas ${ }^{10}$.

Valores de carga crítica são muitas vezes calculados através de modelos de Balanço de Massa Simples (BMS). Este é um modelo de estado estacionário e, conseqüentemente, inclui processos que influenciam a produção e o consumo do ácido durante tempos infini$\operatorname{tos}^{10,16}$.

O critério de carga crítica (CL) é dado pelo balanço de massa de acidez e está representado na Equação (1) ${ }^{17}$. Nas equações a seguir serão utilizadas as notações como nas referências originais.

$[\mathrm{CL}(\mathrm{A})]=\mathrm{W}-\mathrm{ANC}_{\mathrm{L}}$

Onde W é o fator de intemperismo do solo da região e depende de vários fatores, como constituição dos minerais (área específica, temperatura do solo, quantidade e qualidade da água de percolação, concentração de $\mathrm{CO}_{2}$ atmosférico no solo proveniente da biota e propriedades físicas do solo), o que torna sua avaliação complexa ${ }^{17}$. $\mathrm{ANC}_{\mathrm{L}}$ é a capacidade de neutralização alcalina lixiviável do ecossistema (solo), representada pela relação entre os cátions básicos trocáveis (BC) e o alumínio (Equações 2 e 3).

$\mathrm{ANC}_{\mathrm{L}}=\mathrm{BC} / \mathrm{Al}^{3+}$

Sendo $\mathrm{BC}=\mathrm{Ca}^{2+}+\mathrm{Mg}^{2+}+\mathrm{K}^{+}$

$\mathrm{ANC}_{\mathrm{L}}=\left(\mathrm{Ca}^{2+}+\mathrm{Mg}^{2+}+\mathrm{K}^{+}\right) / \mathrm{Al}^{3+}$

O conceito da razão BC/Al surgiu da necessidade de correlacionar quantitativamente a vitalidade de florestas com a acidificação de solos. A partir de dados de laboratório sobre a resposta de plantas à presença de alumínio, observaram-se correlações mais consistentes com parâmetros de crescimento usando a razão $\left(\mathrm{Ca}^{2+}+\mathrm{Mg}^{2+}+\mathrm{K}^{+}\right) /$ $\mathrm{Al}^{3+}$ 16-17.

No BMS, a carga crítica para sistemas terrestres correlaciona a característica química do solo com a resposta da planta via a razão crítica entre cátions básicos e o alumínio (Equação 3). Geralmente, o indicador biológico é a raiz de árvores, sendo que o sódio foi excluído da razão porque se observou que ele não oferece "proteção" para a planta contra os efeitos tóxicos do alumínio?.

Devido a dificuldades de avaliação do termo W, do valor da carga crítica (CL), alguns autores propõem a avaliação parcial da carga crítica para um ecossistema em particular através da relação representada na Equação 3, que é um dos parâmetros utilizados no cálculo da carga crítica. Esse parâmetro passa a ser denominado carga crítica parcial $(\mathrm{CCP})$ e mostra a tolerância da planta pelo alumínio na solução solo ${ }^{16-18}$ :

$$
\mathrm{CCP}=\left(\mathrm{Ca}^{2+}+\mathrm{Mg}^{2+}+\mathrm{K}^{+}\right) / \mathrm{Al}^{3+}
$$

Através do cálculo de CCP é possível estimar a vulnerabilidade do solo da região à deposição ácida de forma simples. O valor limite

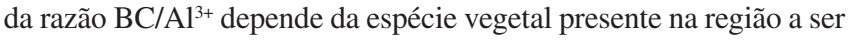
avaliada. Estudos que investigaram essa razão e sua influência no crescimento da planta (resposta da planta) adotaram valores limítrofes entre 1 - 10, dependendo da sensibilidade do vegetal à deposição ácida. Observou-se que espécies vegetais sensíveis não conseguem assimilar adequadamente os nutrientes $\left(\mathrm{Ca}^{2+}, \mathrm{Mg}^{2+} \mathrm{K}^{+}\right)$. Quando a concentração de alumínio aumenta (devido à acidificação), isto é, quando o nível da razão $\mathrm{BC} / \mathrm{Al}^{3+}$ é menor que dez, o alumínio presente torna-se tóxico, ocorrendo diminuição do crescimento das raízes $^{16-18}$.

A razão $\mathrm{BC} / \mathrm{Al}^{3+}$ tem sido determinada para muitas espécies vegetais e quando resulta em limite crítico alto $(\sim 10)$ significa que a espécie vegetal é sensível à acidificação, ou seja, apresenta baixa tolerância ao alumínio. A Tabela 1 apresenta valores limítrofes da razão $\mathrm{BC} / \mathrm{Al}^{3+}$ para as diferentes vegetações, proposto pelo modelo do balanço de massa (BMS) no estado estacionário ${ }^{16-18}$.

Tabela 1. Valores da razão $\mathrm{BC} / \mathrm{Al}^{3+}$ para diferentes tipos de vegetação sugeridos pelo modelo de Balanço de Massa Simples (BMS)

\begin{tabular}{lc}
\hline Tipos de vegetação & Limite $^{\mathrm{BC} / \mathrm{Al}^{3+}}$ \\
\hline Tundra & 2 \\
Floresta de coníferas & 1,5 \\
Floresta subtropical seca $^{3+}$ & 2 \\
Cerrado (Tropical Savannah) & 10 \\
Terrenos alagadiços & 10 \\
Floresta semi-árida & 10 \\
\hline
\end{tabular}

${ }^{\mathrm{a}} \mathrm{BC}=\left(\mathrm{Ca}^{2+}+\mathrm{Mg}^{2+}+\mathrm{K}^{+}\right)$(cátions básicos na solução solo); ${ }^{\mathrm{b}}$ vegetação da região estudada. Tabela adaptada das referências de Sverdrup ${ }^{16-18}$

Quando a espécie vegetal possui alta tolerância ao alumínio, ela é pouco sensível à acidificação e a razão $\mathrm{BC} / \mathrm{Al}^{3+}$ pode atingir valor 1. Isto representa que, para este tipo de vegetação, o alumínio somente se torna fitotóxico quando $\mathrm{BC} / \mathrm{Al}^{3+}$ é menor que 1 . Logo, a espécie vegetal é resistente à presença de alumínio, portanto não haverá alterações na capacidade de absorção dos elementos nutrientes pelas raízes ${ }^{9,16-18}$.

$\mathrm{Na}$ Europa, a relação $\mathrm{BC} / \mathrm{Al}^{3+}=1$ tem sido adotada como valor de carga crítica mínima para regiões com vegetações de coníferas. Esse valor garante que as coníferas estão $95 \%$ protegidas, o que não ocorre com a vegetação rasteira que é mais sensível. A vegetação rasteira pode estar sendo submetida a estresse químico significativo e, portanto, a composição das espécies da vegetação rasteira tende a se alterar ao longo do tempo ${ }^{17}$.

\section{RESULTADOS E DISCUSSÃO}

\section{Composição química de águas de chuva}

Os resultados das concentrações médias e respectivos desvios padrão, medianas, máximos, mínimos e média ponderada pelo volume (MPV) de $\mathrm{SO}_{4}^{2-}, \mathrm{NO}_{3}^{-}, \mathrm{Cl}^{-}, \mathrm{NH}_{4}^{+}, \mathrm{Ca}^{2+}, \mathrm{Na}^{+}, \mathrm{K}^{+}, \mathrm{Mg}^{2+}, \mathrm{H}^{+}$(obtidas a partir das medidas de $\mathrm{pH}$ ) e da condutividade de águas de chuva estão apresentados na Tabela 2 . O coeficiente de variação dos resultados foi alto (de 76 a 191\%), mostrando grande variabilidade nas concentrações das espécies analisadas entre as diferentes amostras ${ }^{7}$.

As espécies com concentrações mais significativas foram: $\mathrm{SO}_{4}^{2-}$, $\mathrm{NH}_{4}^{+}, \mathrm{Na}^{+}$e $\mathrm{Ca}^{2+}$. A presença do sulfato deve-se à combustão do carvão com alto teor de pirita, causando significativas emissões de $\mathrm{SO}_{2}$, o qual é oxidado a $\mathrm{SO}_{4}{ }^{2-}$ na atmosfera.

As prováveis fontes de emissão de amônia na atmosfera são a criação de animais (80\%), o uso de fertilizantes (17\%) e os processos industriais (1\%) que, consequentemente, geram as altas concentrações de $\mathrm{NH}_{4}^{+}$encontradas na água de chuva ${ }^{19}$.

Para detectar possíveis fontes comuns entre os íons presentes nas águas de chuva foi aplicada a matriz de correlação de Pearson ${ }^{7}$. As mais altas correlações foram observadas entre as espécies 
Tabela 2. Concentração mediana, média aritmética, intervalos (mínimo e máximo) e média ponderada por volume (MPV) para as espécies químicas avaliadas em 73 amostras de águas de chuva, correspondentes a 30 eventos de precipitação na região sob influência da termelétrica de Figueira, Brasil (10Mwe).

\begin{tabular}{lcccc}
\hline Íons & Mediana & $\begin{array}{c}\text { Média }( \pm \mathrm{sd}) \\
\mu \mathrm{mol} \mathrm{L}\end{array}$ & $\begin{array}{c}\text { Intervalo } \\
\text { MPV }\end{array}$ & MP \\
\hline $\mathrm{SO}_{4}{ }^{2-}$ & 25 & $37(42)$ & $2,2-304$ & 35 \\
$\mathrm{NO}_{3}{ }^{-}$ & 11 & $17(25)$ & $1,0-155$ & 13 \\
$\mathrm{Cl}^{-}$ & 13 & $17(13)$ & $1,3-70$ & 16 \\
$\mathrm{NH}_{4}^{+}$ & 13 & $29(48)$ & $0,5-269$ & 30 \\
$\mathrm{Ca}^{2+}$ & 7,5 & $17(23)$ & $0,95-123$ & 16 \\
$\mathrm{Na}^{+}$ & 20 & $37(42)$ & $0,4-192$ & 35 \\
$\mathrm{~K}^{+}$ & 8,0 & $11(11)$ & $0,3-48$ & 10 \\
$\mathrm{Mg}^{2+}$ & 2,5 & $6(11)$ & $0,15-59$ & 6 \\
$\mathrm{H}^{+}$ & 9,0 & $18(25)$ & $0,4-115$ & 14 \\
$\mathrm{pH}$ & 5,0 & $4,7(0,7)$ & $3,9-6,4$ & 4,9 \\
\hline
\end{tabular}

$\mathrm{Mg}^{2+} \mathrm{XCa}^{2+}(0,9) ; \mathrm{K}^{+} \mathrm{xMg}^{2+}(0,8) ; \mathrm{K}^{+} \mathrm{xCa}^{2+}(0,8) ; \mathrm{NH}_{4}^{+} \mathrm{xMg}^{2+}(0,8)$; $\mathrm{NH}_{4}^{+} \mathrm{xCa}^{2+}(0,7)$ indicando que a presença destes cátions se deve à mesma fonte, principalmente, aplicação de fertilizantes, processos de calagem (neutralização dos solos ácidos com $\mathrm{CaCO}_{3}$ ), ressuspensão do solo e atividades agropastoris em geral. Correlações significativas também foram observadas entre $\mathrm{SO}_{4}{ }^{2-} \mathrm{x} \mathrm{Ca}^{2+}(0,7) ; \mathrm{SO}_{4}{ }^{2-} \mathrm{x} \mathrm{Cl}$ $(0,7) ; \mathrm{SO}_{4}^{2-} \mathrm{x} \mathrm{Na}{ }^{+}(0,6) ; \mathrm{Na}^{+} \mathrm{x} \mathrm{Cl}-(0,8)^{7}$.

$\mathrm{A}$ análise por fluorescência de raios- $\mathrm{X}$ indicou que as altas concentrações de sódio, assim como de cloreto, nas águas de chuva da região são devidas à dissolução das cinzas volantes emitidas após queima do carvão na termelétrica? .

A Figura 2 apresenta o histograma dos valores de $\mathrm{pH}$ de 73 amostras de águas de chuva, correspondentes a 30 eventos de precipitação, coletadas durante um ano. $\mathrm{O}$ valor do $\mathrm{pH}$ da água de chuva da região variou entre 3,9 e 6,4 apresentando valor médio de 4,7 \pm 0,7, com coeficiente de variação de $15 \%$. Em grande número de eventos de chuva (70\%) mediram-se valores de $\mathrm{pH} \leq 5,6$, indicando características de chuva ácida na precipitação da região.

$\mathrm{O}$ principal fator de contribuição ácida é o sulfato; sendo $\mathrm{Ca}^{2+}$, $\mathrm{Na}^{+}$e $\mathrm{NH}_{4}^{+}$(carbonatos e hidróxidos) os cátions precursores básicos mais relevantes para a neutralização da chuva ácida da região. A presença de altas concentrações de sulfato na água de chuva tende a tornar o meio mais ácido. Como se pode observar, os valores de $\mathrm{pH}$

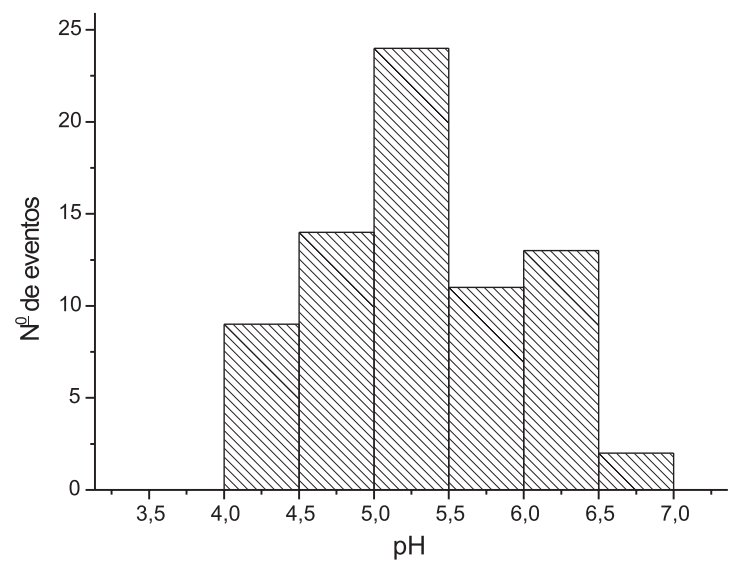

Figura 2. Histograma dos valores de pH de 73 amostras de águas de chuva, coletadas durante o período de Junho de 1999 a Junho de 2000, na região da Termelétrica de Figueira, Paraná encontrados não foram tão baixos quanto os esperados, indicando que provavelmente espécies alcalinas, como hidróxidos e carbonatos de $\mathrm{Ca}^{2+}$ e $\mathrm{NH}_{3}$, estejam neutralizando a ação ácida do sulfato.

É importante lembrar que, apesar de indicar neutralização da acidez da água de chuva, o íon amônio quando atinge o solo, por processos de nitrificação, pode liberar maior quantidade de íons $\mathrm{H}^{+}$, do que apenas a dissolução do ácido sulfúrico. Portanto, no solo, a deposição de sulfato de amônio, ao longo do tempo resulta em efeito negativo semelhante ao da deposição de ácido sulfúrico ${ }^{20}$.

As deposições anuais das espécies iônicas avaliadas nas águas de chuva da região de Figueira não foram calculadas devido à não amostragem de $100 \%$ da precipitação do período. Porém, para o sulfato a deposição é significativa, pois a média ponderada pelo volume

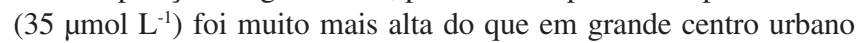
como São Paulo ${ }^{21}\left(9,5 \mu \mathrm{mol} \mathrm{L}^{-1}\right)$, ambos com taxas de precipitação anuais da mesma ordem $(\sim 1400 \mathrm{~mm} / \mathrm{ano})$.

A deposição do $\mathrm{SO}_{4}^{2-}$ não é importante apenas por estar associado à acidez $\left(\mathrm{H}^{+}\right)$, mas também porque facilita a lixiviação de cátions. O sulfato é um ânion relativamente móvel, e acompanha a troca de cátions por $\mathrm{H}^{+}$, seja da vegetação ou do solo. A deposição do $\mathrm{SO}_{4}^{2-}$ pode, portanto, aumentar a lixiviação tanto de cátions ácidos $\left(\mathrm{H}^{+} \mathrm{e}\right.$ $\left.\mathrm{Al}^{3+}\right)$ como dos cátions básicos $\left(\mathrm{Ca}^{2+}, \mathrm{Mg}^{2+}, \mathrm{K}^{+} \mathrm{e} \mathrm{Na}^{+}\right)$. Os cátions básicos estão também entre os nutrientes majoritários das plantas. A lixiviação desses nas folhagens (os quais são inicialmente derivados do solo) e no solo, devido à deposição dos ânions sulfato, resulta em ambos: acidificação e perda da fertilidade do solo ${ }^{22}$.

\section{CARGA CRÍTICA DO SOLO}

O perfil das concentrações dos cátions $\mathrm{Ca}^{2+}, \mathrm{K}^{+}, \mathrm{Mg}^{2+}$ e $\mathrm{Al}^{3+}$ biodisponíveis no solo, obtidas por extração com solução de EDTA$\mathrm{NH}_{4}^{+}$, em função da distância da usina estão apresentadas na Figura 3a. As concentrações médias biodisponíveis desses cátions no solo foram 1001, 148, 185 e $271 \mathrm{mg} \mathrm{kg}^{-1}$, respectivamente. As altas concentrações de $\mathrm{Ca}^{2+}$ confirmam sua maior disponibilidade para a maioria das soluções solo. Observou-se que as concentrações de $\mathrm{Al}^{3+}, \mathrm{K}^{+}$

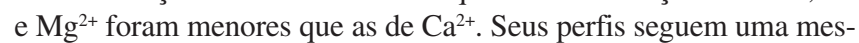
ma tendência, com exceção dos pontos 800 e 900, onde concentrações de $\mathrm{Al}^{3+}$ foram superiores às concentrações de $\mathrm{Ca}^{2+}$. A relação $\mathrm{Ca}^{2+} / \mathrm{Al}^{3+}$ apresentou tendência antagônica, ou seja, quando a concentração de alumínio aumentou muito a concentração de cálcio também diminuiu abruptamente. Este comportamento diferenciado pode explicar a maior acidez (valores de $\mathrm{pH}$ menores) medida em ambos os pontos de amostragem (Figuras 3a e c).

A caracterização das propriedades resultou em solo francofrancoargilosa com $39 \pm 11 \%$ de areia, $37 \pm 5 \%$ de silte e $24 \pm 11 \%$ de argila, mineral com matéria orgânica $(\mathrm{MO}=4,6 \pm 1,3 \%)$, acidez muito alta $(\mathrm{pH}=4,4 \pm 0,4)$, resultando em capacidade de troca catiônica média $\left(\mathrm{CTC}=22 \pm 4 \mathrm{cmol} \mathrm{kg}^{-1}\right)$. Os resultados dessas características para cada ponto de amostragem estão apresentados nas Figuras 3b (\% de areia, silte e argila e CTC) e 3c (pH e MO).

$\mathrm{Na}$ avaliação da razão $\mathrm{BC} / \mathrm{Al}^{3+}$ da região em estudo, os valores de CCP variaram entre $1-11$, com valor médio de 5,14 . A partir da Figura 3c, observa-se que $60 \%$ dos valores de CCP estão entre $4-6$. Os pontos 800 e 900 apresentaram valores mais críticos ( 1), coincidentes com valores de cálcio e $\mathrm{pH}$ mais baixos.

Na região de Figueira o tipo de vegetação local é predominantemente cerrado (Tropical Savannah), sendo o valor limítrofe da razão sugerido pelo modelo (BMS - Tabela 1) para esta vegetação BC/Al ${ }^{3+}$ $=10$. $\mathrm{O}$ valor limite 10 indica que o solo em questão apresenta altas concentrações de $\mathrm{Ca}^{2+}, \mathrm{Mg}^{2+}, \mathrm{K}^{+}$e é capaz de neutralizar o efeito da deposição ácida e assim proteger o desenvolvimento da vegetação local (cerrado). 

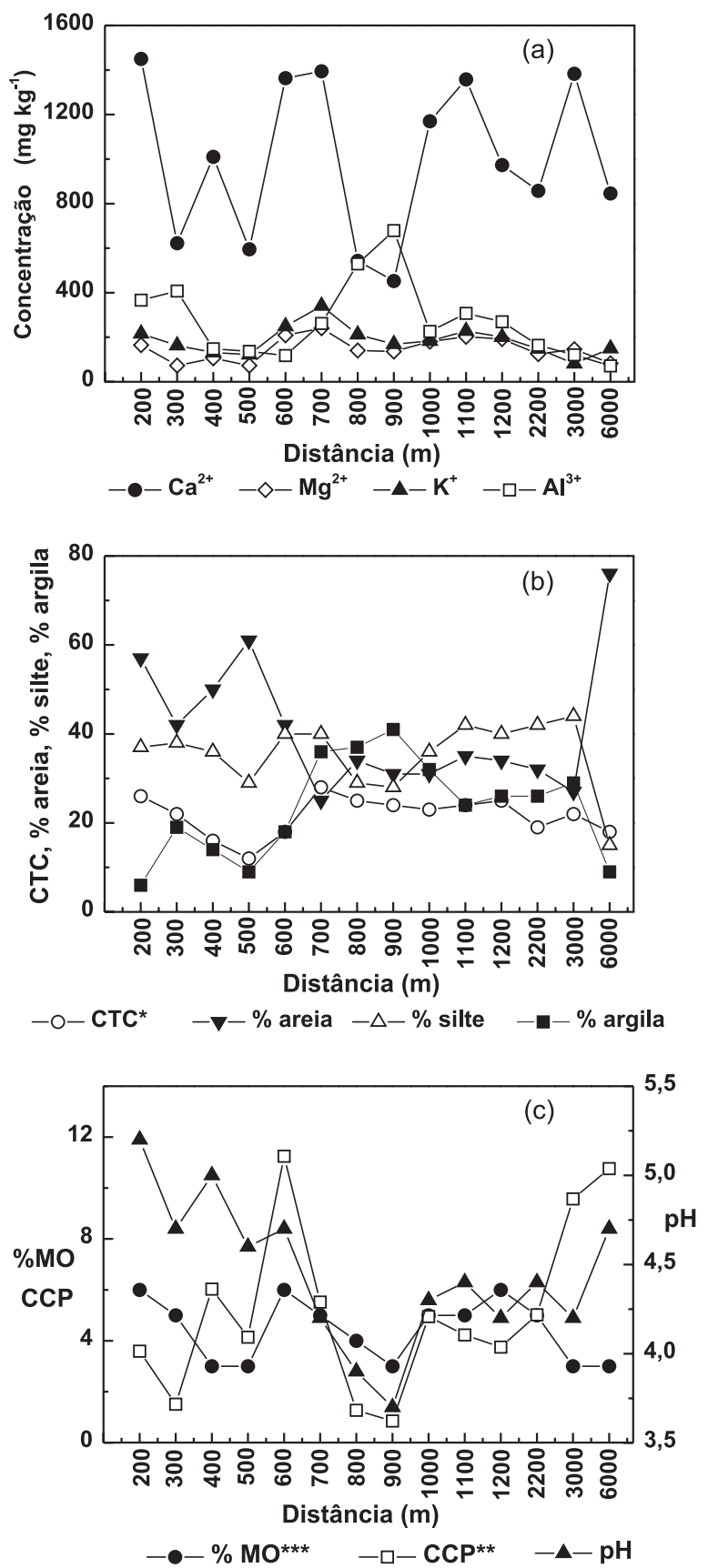

Figura 3. Variação da concentração biodisponível de cátions no solo (3a), caracterização do solo ( $3 b$ e c) e CCP, (3c) em função da distância da Termelétrica. *CTC (capacidade de troca catiônica) $\left(\mathrm{cmol} \mathrm{kg}^{-1}\right)$; ** CCP = $\mathrm{BC} / \mathrm{Al}^{3+}\left(\mathrm{cmol} \mathrm{kg}^{-1}\right)$, onde $\mathrm{BC}=\left(\mathrm{Ca}^{2+}+\mathrm{Mg}^{2+}+\mathrm{K}^{+}\right) ; * * * \mathrm{MO}$ (porcentagem de matéria orgânica do solo).

Comparando-se o valor limítrofe estabelecido pelo modelo para o tipo de vegetação cerrado (Tropical Savannah) com o resultado da

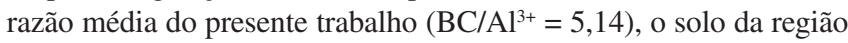
pode ser considerado susceptível a deposição ácida, podendo afetar a vegetação da região ao longo do tempo.

\section{CONCLUSÃO}

As águas de chuva apresentaram altas concentrações de $\mathrm{SO}_{4}{ }^{2-}$ em todos os eventos amostrados. Valores de $\mathrm{pH}$ inferiores a 5,6 ob- servados em $70 \%$ das amostras caracterizaram a chuva da região como levemente ácida devido à influência das atividades da Termelétrica na região (fonte de $\mathrm{SO}_{2}$, o qual é oxidado no ar formando $\mathrm{H}_{2} \mathrm{SO}_{4}$, componente importante da chuva ácida). No entanto o grau de acidez da deposição úmida na região não se mostrou tão crítico quanto o esperado, devido às concentrações significativas dos cátions $\mathrm{NH}_{4}^{+} \mathrm{e} \mathrm{Ca}^{2+}$, potenciais neutralizadores da ação ácida do sulfato nas águas de chuva, a partir de amônia e carbonatos/hidróxidos de cálcio presentes na atmosfera local.

Para avaliação completa da susceptibilidade do solo e da vegetação é imprescindível a aplicação de modelos matemáticos, os quais exigem grande quantidade de informações e que em alguns casos ainda não estão disponíveis na literatura. Porém, a avaliação parcial da susceptibilidade do solo de Figueira apresentou CCP média = 5,14 . Isto significa que o solo e o tipo de vegetação (cerrado) da região são sensíveis à deposição ácida. A ação prolongada dessas condições agressivas de chuva ácida na região pode ser prejudicial para a fertilidade, a qualidade do solo e o desenvolvimento da vegetação local.

\section{AGRADECIMENTOS}

Ao apoio técnico e logístico da Companhia Carbonífera Cambuí, empresa responsável pelo gerenciamento da Termelétrica Figueira, no trabalho de amostragens de águas de chuva e solo. Ao CNPq pela bolsa de mestrado para P. Hama e à FAPESP pela bolsa de pósdoutorado de A. Fornaro (processo 98/13421-2).

\section{REFERÊNCIAS}

1. Saldanha, A. J.; Estudo para estabelecimento da política de longo prazo para a produção e uso do carvão mineral nacional, Secretaria de Energia, Minas e Comunicação do Estado do Rio Grande do Sul: Porto Alegre, 1988.

2. IAIC - Informativo Anual da Indústria Carbonífera, Departamento Nacional da Produção Mineral - Brasília, 1994, p.195-215.

3. UNSCEAR - Ionizing Radiations Sources and Biological Effects, United Nations Scientific Committee on the Effects of Atomic Radiation, United Nations: New York , 1988, p. 81-86.

4. Charlson, R. J.; Rodhe, H.; Nature 1982, 295, 683; Likens, G. E.; Chem. Eng. News 1976, 22, 29; Seinfeld, J. H.; Atmospheric Chemistry and Physics of Air Pollution, John Willey: New York, 1986.

5. Barron, J.; Denning, A. S.; Atmos. Environ. 1993, 27A, 2337.

6. Alastuey, A.; Querol, X.; Chaves, A.; Ruiz, C. R.; Carratala, A.; LopezSoler, A.; Environ. Pollut. 1999, 106, 359.

7. Flues, M.; Hama, P.; Lemes, M. J. L.; Dantas, E. S. K.; Fornaro, A.; Atmos. Environ. 2002, 36, 2397.

8. Cresser, M. S.; Sci. Total Environ. 2000, 249, 51.

9. Reynolds, B.; Sci. Total Environ. 2000, 253, 169.

10. van der Salm, C.; de Vries, W.; Sci. Total Environ. 2001, 271, 11.

11. Nilsson, J.; Grennfelt, P.; eds., Crítical loads for sulphur and nitrogen: Report from a Workshop held at Skokloster, Sweden, 19-24 March 1988. Nordic Council of Ministers: Copenhagen, 1988.

12. Klute, A.; Methods of Soil Analysis Part 1, Physical and Mineralogical Methods, Particle Size Analysis: Wiscosin, 1986, p. 383-411.

13. EMPRAPA - Manual de Métodos de Análise de Solo, 2a . ed., 1997.

14. Hesse, P. P.; A text Book of soil Analysis, J. Murray: London, 1971, p. 102103.

15. Ure, A. M.; Quevauviller, P. H.; Muntau, H.; Griepink, B.; Int. J. Environ. Anal. Chem. 1993, 51, 135.

16. Sverdrup, H.; Warfvinge, P.; Reports in Ecology and Environmental Engineering, 1993, Dep. Chem. Eng. II, Lund University: Sweden, 1993, p. $1-123$.

17. Sverdrup, H.; Warfvinge, P.; Ecol. Bul. 1995, 44, 75.

18. Hettelingh, J. P.; Sverdrup, H.; Zhao, D.; Water, Air, Soil Pollut. 1995, 85, 2565.

19. Blume, H. P.; Handbuch des Bodenschutzes, Ecomed: München, 1992, p. 247-248.

20. Galloway, J. N.; Water, Air, Soil Pollut. 1995, 85, 15.

21. Fornaro, A.; Gutz, I. G. R.; Atmos. Environ. 2003, 37, 117.

22. Piirainen, S.; Finer, L.; Starr, M.; Water, Air, Soil Pollut. 2002, 133, 185. 